\title{
Erratum
}

\section{Erratum to "Prevalence and Associated Factors of Tuberculosis in Prisons Settings of East Gojjam Zone, Northwest Ethiopia"}

\author{
Emirie Hunegnaw, ${ }^{1}$ Moges Tiruneh, ${ }^{2}$ and Mucheye Gizachew $\mathbb{D}^{2}$ \\ ${ }^{1}$ Laboratory Section, Motta Hospital, Motta, Ethiopia \\ ${ }^{2}$ Department of Medical Microbiology, School of Biomedical and Laboratory Sciences, College of Medicine and Health Sciences, \\ University of Gondar, P.O. Box 196, Gondar, Ethiopia
}

Correspondence should be addressed to Mucheye Gizachew; muchegiza@gmail.com

Received 30 April 2018; Accepted 7 May 2018; Published 9 August 2018

Copyright (C) 2018 Emirie Hunegnaw et al. This is an open access article distributed under the Creative Commons Attribution License, which permits unrestricted use, distribution, and reproduction in any medium, provided the original work is properly cited.

In the article titled "Prevalence and Associated Factors of Tuberculosis in Prisons Settings of East Gojjam Zone, Northwest Ethiopia" [1], the order of the authors was incorrect. Additionally, the name of the corresponding author was given incorrectly as Mucheye Gizachew Beza. The author's name should have been written as Mucheye Gizachew. The revised authors' list and affiliations are shown above.

\section{References}

[1] M. G. Beza, E. Hunegnaw, and M. Tiruneh, "Prevalence and Associated Factors of Tuberculosis in Prisons Settings of East Gojjam Zone, Northwest Ethiopia," International Journal of Bacteriology, vol. 2017, Article ID 3826980, 7 pages, 2017. 


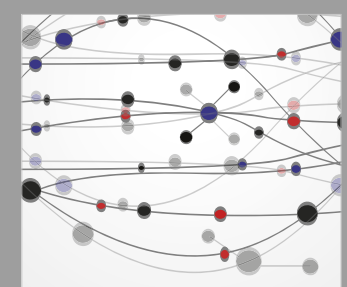

The Scientific World Journal
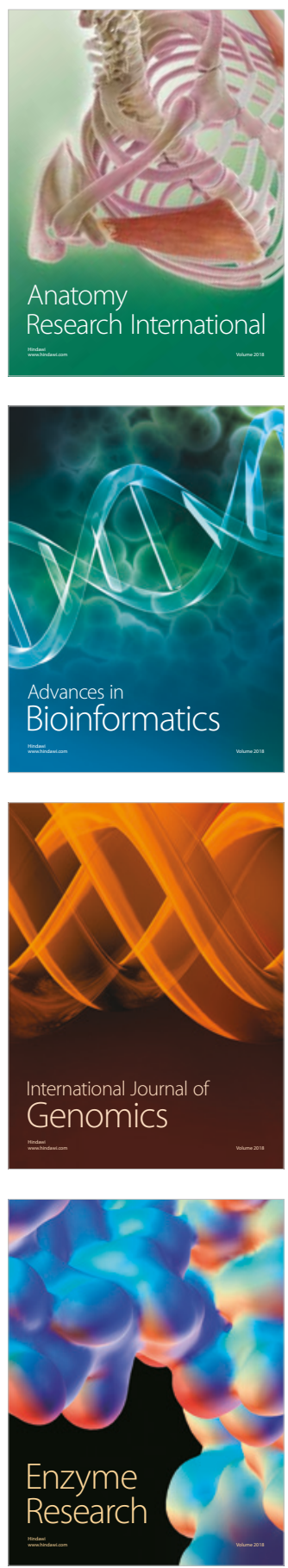
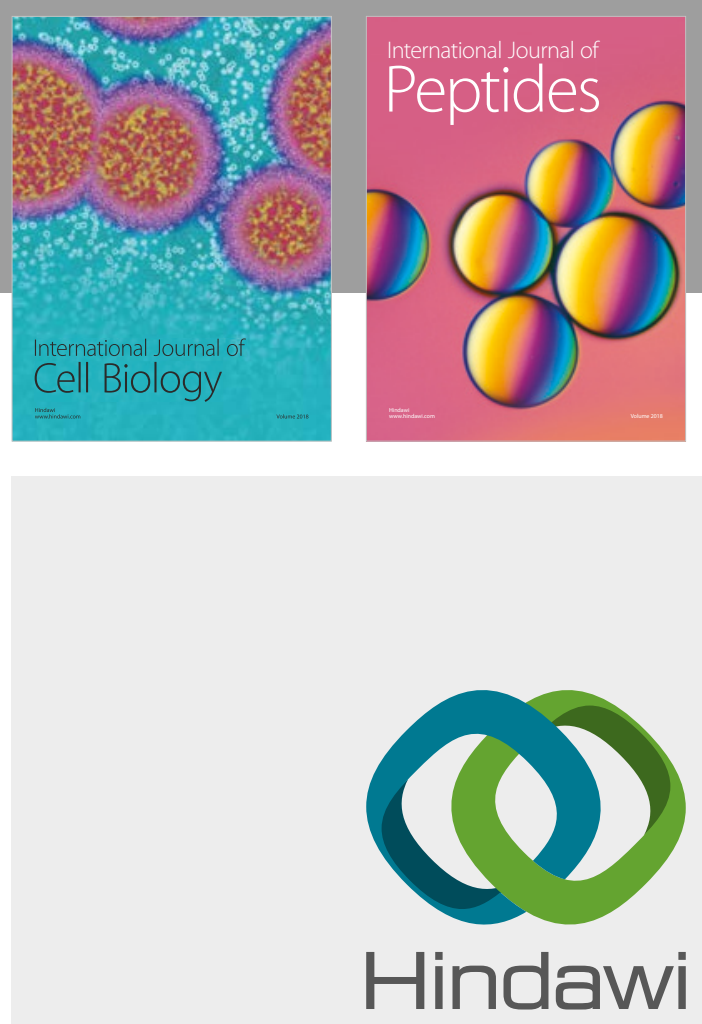

Submit your manuscripts at

www.hindawi.com
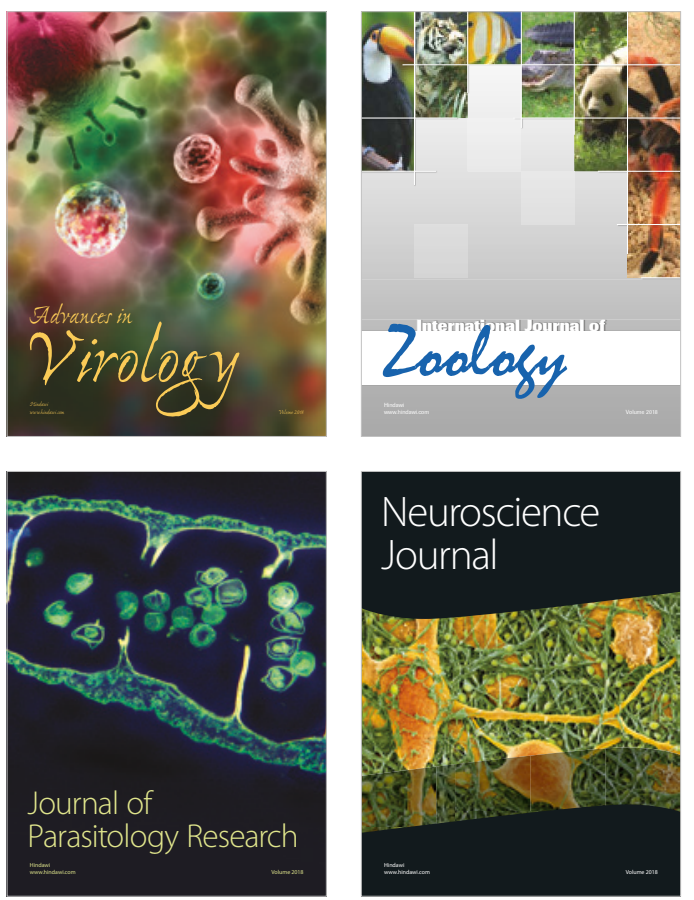
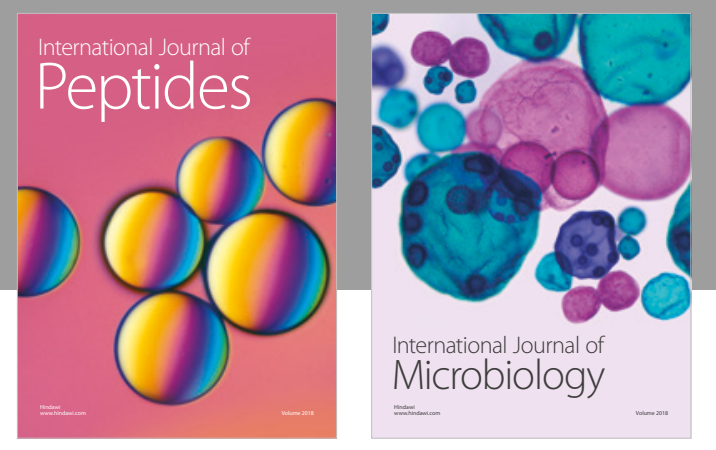

nternational Journal of Microbiology
Journal of
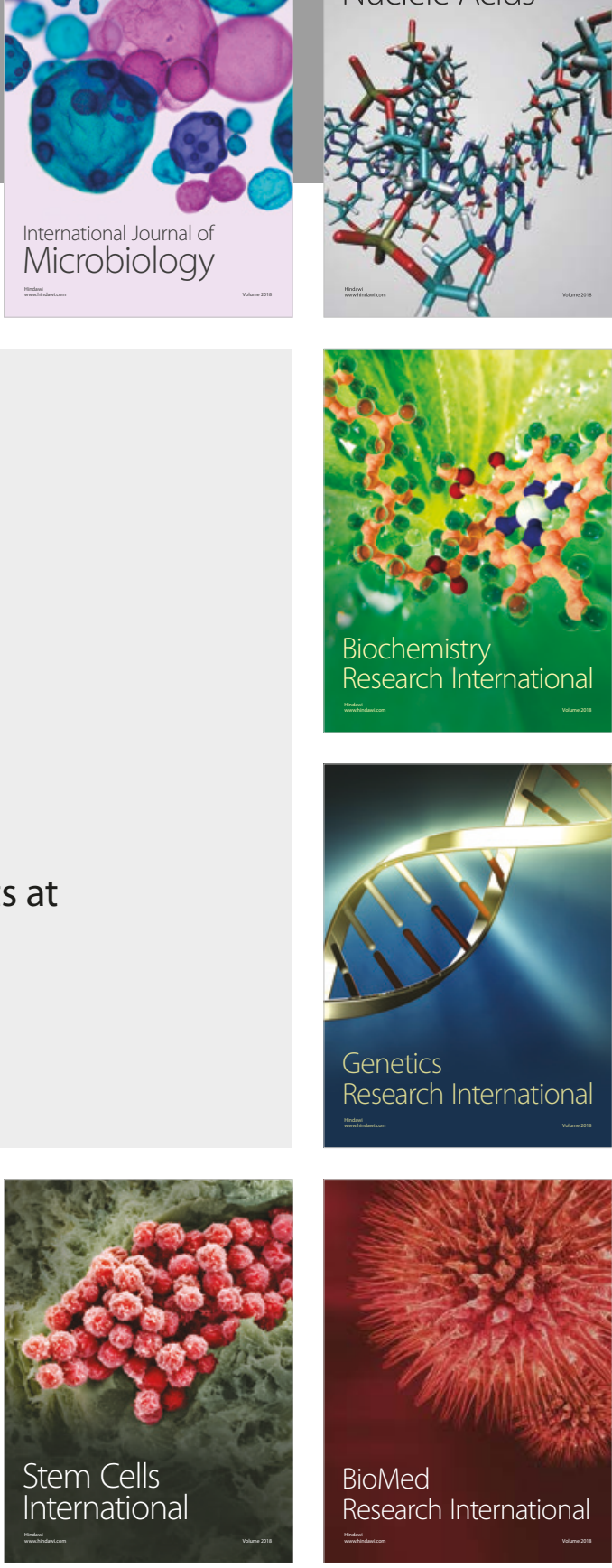
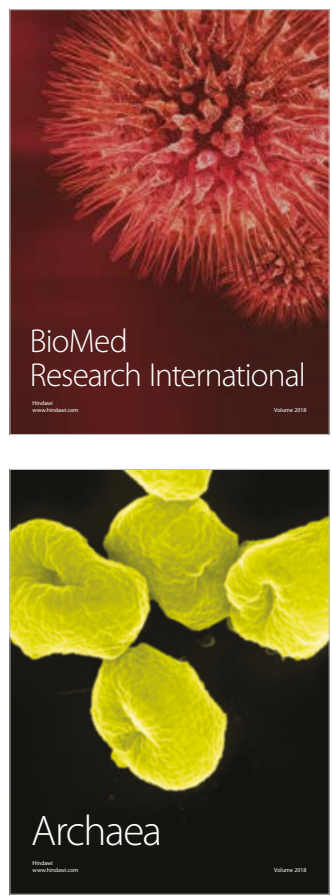